\title{
Etnobotânica e urbanização: conhecimento e utilização de plantas de restinga pela comunidade nativa do distrito do Campeche (Florianópolis, SC)
}

Elisa Serena Gandolfo ${ }^{1,2}$ e Natália Hanazaki ${ }^{2,3}$

Recebido em 4/11/2010. Aceito em 27/01/2011

\begin{abstract}
RESUMO
(Etnobotânica e urbanização: conhecimento e utilização de plantas de restinga pela comunidade nativa do Distrito do Campeche (Florianópolis, SC)). A ocupação da faixa litorânea do Brasil vem apresentando nas últimas décadas um grande incremento populacional, levando a urbanização de áreas anteriormente ocupadas por populações tradicionais. O objetivo deste trabalho foi investigar o conhecimento etnobotânico sobre espécies de restinga de representantes da comunidade local de descendentes de açorianos do Distrito do Campeche (Florianópolis, SC), área em processo de urbanização acelerado. Foram selecionados informantes através de amostragem intencional, sendo realizadas 15 entrevistas com moradores nativos entre 42 e 84 anos. Constatou-se que os moradores nativos que vivenciaram a realidade rural na área detêm um conhecimento etnobotânico das plantas de restinga relacionado aos tempos antigos, onde várias espécies eram utilizadas para a manutenção da sobrevivência no local, mas continuam incrementando este conhecimento com plantas utilizadas ainda atualmente, principalmente na categoria medicinal. Do passado rural para o presente urbano a frequência de uso das espécies citadas diminuiu consideravelmente, o que pode acarretar perda de conhecimento etnobotânico entre as futuras gerações. A pesquisa etnobotânica em áreas em transformação contribui para a valorização da cultura local e pode agregar valor cultural à vegetação de restinga, somando esforços para a conservação deste ecossistema.
\end{abstract}

Palavras-chave: Áreas costeiras, descendentes de açorianos, dinâmica cultural

\begin{abstract}
(Ethnobotany and urbanization: knowledge and use of restinga plants by the native community of Distrito do Campeche (Florianópolis, Santa Catarina, Brazil)). The occupation of the Brazilian coastline has increased greatly over the past decades, leading to urbanization of areas previously occupied by traditional populations. This study aimed to investigate the ethnobotanical knowledge of restinga species of members of the local community of Azorean descendents living in the Campeche District (Florianopolis, Santa Catarina, Brazil), an area suffering from an accelerated process of urbanization. We selected informants through purposive sampling and we did 15 interviews with native residents from 42 to 84 years old. The native residents that experienced the past rural reality in the area have ethnobotanical knowledge of restinga plants related to times gone by, when many species were used for their maintenance and survival, but they are also increasing this knowledge with plants currently in use, mainly in the medicinal category. From the rural past to the urban present, use frequency of cited plants decreased considerably, which may cause a loss of ethnobotanical knowledge among future generations. Ethnobotanical research in changing areas contributes to the valorization of local cultures and can attach cultural value to restinga vegetation, thus contributing to the conservation of this ecosystem.
\end{abstract}

Key words: Coastal areas, Azorean descendents, cultural dynamics

1 Universidade Federal de Santa Catarina, Centro de Ciências Biológicas, Programa de Pós-Graduação em Biologia Vegetal, Departamento de Botânica, Florianópolis, SC, Brasil

2 Universidade Federal de Santa Catarina, Departamento de Ecologia e Zoologia, Laboratório de Ecologia Humana e Etnobotânica, Florianópolis, SC, Brasil

3 Autor para correspondência: natalia@ccb.ufsc.br 


\section{Introdução}

A ocupação acelerada de regiões litorâneas tem resultado num intenso processo de urbanização, tanto nacionalmente como internacionalmente (Strohaecker 2008), modificando o modo de vida de diversas comunidades humanas antes relativamente isoladas como, por exemplo, comunidades de pescadores e agricultores. Ao relacionar a urbanização às mudanças na forma de vida de populações caiçaras no litoral dos estados de São Paulo e Rio de Janeiro, Diegues (2004) cita as migrações da população das praias e "sítios" para as cidades litorâneas, estabelecendo bairros urbanos e periurbanos. Em outras situações, como é o caso de localidades outrora rurais da Ilha de Santa Catarina (Florianópolis, SC), foi principalmente a expansão do núcleo urbano do município que levou à transformação de tais áreas, alterando o modo de vida das populações locais, e à necessária adaptação ao meio urbano.

$\mathrm{O}$ avanço das cidades no litoral ameaça os ecossistemas costeiros, áreas consideradas como prioritárias para a conservação por representarem a zona de transição entre o ambiente marinho e o terrestre, apresentando alta diversidade e complexidade (MMA/SBF 2002). A Ilha de Santa Catarina é classificada como área prioritária para a conservação, utilização sustentável e repartição de benefícios, como parte da Zona Marinha e Costeira (MMA/SBF 2002). A fitofisionomia dominante da porção oriental da Ilha de Santa Catarina é a restinga, ambiente que vem sendo ameaçado desde o início da colonização européia por sua proximidade com os primeiros povoamentos e cidades e pela maior facilidade de ocupação quando comparada às áreas de floresta, situação agravada na atualidade pela especulação imobiliária nas áreas litorâneas (Falkenberg 1999). Falkenberg (1999) alerta ainda para a fragilidade deste ecossistema, considerando-o como a formação vegetacional mais destruída e ameaçada das regiões sul e sudeste.

Dentre os povos tradicionais não-indígenas habitantes da zona costeira do Brasil encontram-se os açorianos, descendentes de imigrantes das Ilhas de Açores e Madeira, que chegaram ao Brasil em meados do século XVIII e se fixaram em áreas do litoral de Santa Catarina e do Rio Grande do Sul, onde praticavam basicamente a agricultura de subsistência, mesclando conhecimentos provenientes de sua cultura de origem com conhecimentos indígenas, como na produção da farinha de mandioca (Diegues \& Arruda 2001). Atualmente vivendo em áreas urbanizadas, os descendentes de antigas populações tradicionais perdem as principais características que as definiam como tal, porém mantém a memória dos tempos pré-urbanos, dando continuidade a determinados traços culturais que perduram mesmo em meio à nova realidade heterogênea típica das zonas urbanas.

Embora no passado a população rural tenha causado transformações intensas no ambiente, em sua prática diária de trabalho na agricultura estabelecia uma relação direta com os elementos naturais, desenvolvendo dessa forma um conhecimento local sobre a biodiversidade. No novo cenário urbano tais conhecimentos passam a não ser mais de valor essencial para a sobrevivência, sofrendo o risco de perderem-se no tempo sem terem sido registrados.

A etnobotânica é um ramo da ciência que investiga a relação entre pessoas e plantas em sistemas dinâmicos (Alcorn 1995; Hanazaki 2004). Através de estudos etnobotânicos pode-se levantar informações sobre substâncias de origem vegetal com aplicações médicas e farmacológicas, sobre formas de manejo e conservação, sobre cultivares manipulados tradicionalmente (Albuquerque 2005), entre outras. Em ambientes em transformação ambiental e social a etnobotânica pode contribuir para o registro de informações relacionadas às interações entre pessoas e plantas, evitando que tais informações sejam perdidas frente a novos contextos.

Uma vez que tanto a cultura quanto a paisagem não são estáticas, as condições para produção de conhecimento etnobotânico também são dinâmicas. Em casos de áreas em transformação, a pesquisa etnobotânica pode levantar questões importantes para a conservação de áreas naturais nos interstícios da malha urbana, contribuindo com a inserção de valores relacionados à importância cultural de tais áreas para a população residente. Dessa forma pode contribuir tanto para a manutenção da qualidade de vida quanto para a identificação dos grupos culturais que persistem no local, possibilitando a continuidade da dinâmica de elaboração e re-elaboração do conhecimento etnobotânico.

Este artigo tem como objetivo investigar o conhecimento sobre plantas de restinga de representantes de uma antiga comunidade de pescadores/agricultores que se encontra em processo acelerado de urbanização, buscando registrar tal conhecimento, bem como analisar a frequência de utilização destas plantas no passado e no presente. Espera-se que a população tradicional local, tendo vivido o período anterior a urbanização, quando as atividades principais giravam em torno da agricultura e da pesca, tenham conhecimento acerca da vegetação local, adquirido pela convivência diária com o ambiente natural e pela necessidade de obtenção de produtos para a manutenção da vida no local.

\section{Área de Estudo}

O Distrito do Campeche pertence ao município de Florianópolis (SC), tendo sido criado pela Lei 4805/95. Está localizado a cerca de $20 \mathrm{~km}$ do centro da cidade. Situado numa faixa paralela ao mar, possui área aproximada de $35,32 \mathrm{~km}^{2}$. Estende-se por 3.800 metros de praia, até o campo de dunas da Lagoa da Conceição ao norte. Fazem parte do Distrito do Campeche as localidades Morro das Pedras, Praia do Campeche, Campeche e Rio Tavares (IPUF 2009).

A maior parte da região caracteriza-se pela feição plana, formada pela deposição de sedimentos arenosos durante os sucessivos avanços e recuos do mar. Sob a cobertura arenosa 
encontra-se o Aquífero Campeche, formando a Bacia Hidrogeológica do Campeche, a qual aflora formando as lagoas Pequena e da Chica, e pequenos córregos que em tempos passados desembocavam na praia em períodos de cheia e atualmente estão em contínuo processo de assoreamento causado por construções ao longo de seus leitos originais (Barbosa 2007). A formação vegetacional predominante na área é a restinga, tendo ainda uma pequena porção de manguezal e floresta ombrófila densa.

Não existem registros sobre o início do povoamento do Campeche, nem tampouco se sabe o número exato de pessoas que viviam na região antes de 1980. Segundo estudo realizado para o Instituto de Planejamento Urbano de Florianópolis (Campanário 2007), a população era de 4.816 habitantes em 1980, passando para $8.174 \mathrm{em} \mathrm{1990,}$ 21.484 em 2000 e com projeção de 34.738 em 2010. Segundo Neves (2003), o atual Distrito do Campeche teve o início de sua formação por volta de 1880, no final do século XIX, com a chegada de famílias vindas da região da Lagoa da Conceição, área densamente ocupada por imigrantes açorianos desde 1750, sendo sua população inicial de aproximadamente 19 famílias.

Os moradores do Campeche pertencentes às famílias mais antigas do local são chamado "nativos" no linguajar local, termo utilizado para designá-los também neste artigo. Nas últimas décadas, devido ao crescimento do turismo e ao aumento populacional na Ilha de Santa Catarina, a especulação imobiliária trouxe uma nova feição à região da planície do Campeche, modificando a paisagem e o modo de vida da comunidade local.

\section{Material e métodos}

Para a seleção de informantes foi realizada amostragem intencional, que segundo Tongco (2007) é um método não probabilístico de escolha de informantes, de acordo com as qualidades que possuem e que sejam fundamentais para responder questões específicas da pesquisa, sendo um método que poupa esforços quando as informações relevantes são exclusivas de certos representantes dentro de uma sociedade. Os critérios para a seleção de informantes foram ser considerado nativo do Campeche, ter mais que 40 anos e algum conhecimento sobre plantas. Os informantes foram encontrados através de indicações, primeiro através de lideranças locais que propiciaram um primeiro contato (um político e dois comerciantes), depois através dos próprios informantes.

Cada pessoa indicada era convidada a participar da pesquisa em um primeiro contato onde eram expostos os objetivos da mesma, e sua participação era condicionada ao aceite do termo de consentimento prévio, onde era assegurada a participação livre e espontânea e a liberdade em desistir de participar a qualquer momento, bem como a não utilização dos dados para fins monetários. Foram realizadas três entrevistas piloto para adequação do formulário em junho de 2008, e para a sequência de indicações foram realizadas diferentes entradas evitando que os informantes se restringissem a apenas uma parcela da população, como grupos familiares ou vizinhos próximos.

A coleta de dados foi realizada através de entrevistas semi-estruturadas (Alexiades 1996; Albuquerque et al. 2008), seguidas por turnê-guiada (Alexiades 1996; Albuquerque et al. 2008) para complementação de informações, coleta e identificação de plantas. As entrevistas semi-estruturadas abordaram aspectos sócio-econômicos dos entrevistados e um inventário sobre as plantas propriamente ditas, onde o informante foi solicitado a lembrar de plantas nativas que conhecia na região e de suas possíveis utilidades, além de outras informações, como a frequência de uso, buscando diferenciar a utilização no passado e no presente. As plantas coletadas e identificadas foram depositadas no herbário FLOR (UFSC), vouchers 37948 a 37966 e no acervo do Laboratório de Ecologia Humana e Etnobotânica (ECZ/CCB/ UFSC), vouchers 971 a 1206. A classificação em famílias foi realizada através do sistema APG II (Souza \& Lorenzi 2005). Os dados foram coletados entre o período de junho de 2008 a setembro de 2009.

Os dados foram analisados de forma qualitativa e quantitativa. As informações utilizadas para a análise qualitativa foram obtidas através das entrevistas, associadas à observação direta da comunidade e à bibliografia (Amora 1996; Neves 2003). Os dados qualitativos foram codificados e sistematizados para possibilitar a discussão dos principais aspectos relacionados às interações da comunidade local com a vegetação de restinga.

Para análise da suficiência amostral do número de entrevistados foi utilizada curva de rarefação referente às espécies de restinga citadas, associada ao índice de Chao 1 (Chao 1984). As curvas de rarefação adaptadas para uso em estudos etnobotânicos consideram cada informante uma unidade amostral (Peroni et al. 2008), enquanto que o índice de Chaol estima a riqueza total de espécies a partir da riqueza observada, através do cálculo da riqueza observada considerando o quadrado do número de espécies representadas por apenas um indivíduo nas amostras dividido pelo dobro do número de espécies representadas por dois indivíduos nas amostras (Santos 2003). A curva de rarefação foi realizada com o uso do software EcoSim (Gotelli \& Entsminger 2001). Para a comparação da frequência de uso no passado e no presente foi utilizado o teste chi-quadrado para independência.

\section{Resultados e discussão}

\section{Os moradores tradicionais e a urbanização}

Foram realizadas 15 entrevistas com moradores nativos do Campeche, sendo seis mulheres e nove homens, dos quais 12 realizaram também a turnê-guiada, seis mulheres e seis homens. Os obstáculos encontrados durante o processo, 
como as recusas e informantes que não indicaram outra pessoa, foram contornados pedindo-se às pessoas que se recusaram a participar que indicassem outra pessoa ou estabelecendo novas entradas. As pessoas que se recusaram a participar alegaram falta de tempo ou desconhecimento; nesse caso é interessante notar que duas pessoas disseram que outros representantes da comunidade que já haviam sido entrevistados "sabiam muito mais" ou "já tinham falado tudo".

A renda mensal, proveniente na maioria dos casos da aposentadoria $(\mathrm{n}=12)$, varia entre 1 a 15 salários mínimos. Apenas um informante obtém sua renda através de atividades comerciais e dois complementam a renda através da locação de imóveis. Quanto à escolaridade, três informantes são analfabetos, oito estudaram até o $4^{\circ}$ ano do ensino fundamental e dois cursaram o ensino fundamental completo. Apenas dois informantes possuem nível superior, sendo estes os mais jovens (42 e 57 anos). Esse dado reflete as dificuldades enfrentadas no passado, quando a única escola que funcionava na região só oferecia turmas até o $4^{\circ}$ ano do ensino fundamental, como declarado pelos informantes. Aqueles que pretendessem continuar os estudos enfrentavam a dificuldade do transporte, tendo que andar longas distâncias a pé ou de carro de boi para o centro da cidade, sendo que alguns nessa fase optavam por mudar a moradia para o centro da cidade a fim de completar os estudos. O transporte público regular só chegou à região em 1972 e a Escola Básica em 1982 (Amora 1996).

Os informantes desta pesquisa vivenciaram as transformações ocorridas na transição do ambiente rural para o urbano, sendo que os mais velhos chegaram a viver ativamente a realidade rural durante a idade adulta, enquanto os mais jovens detêm lembranças da infância, tendo já vivido outra realidade a partir da juventude, inclusive cursando nível superior e tendo consequentemente profissões ligadas a outros setores, como o comércio ou a política.

Tendo a base da subsistência ligada à agricultura e à pesca, a comunidade que se fixou na região desde o século XIX fazia uso intenso do solo, o que é refletido pela fala dos informantes, quando afirmam que antigamente na região "era só roça" (informante 1, 84 anos; informante 12, 75 anos; informante 15, 69 anos), ou que a vista do Morro do Lampião, área alta em que é possível visualizar a planície inteira, via-se "só quadradinhos" (informante 6, 71 anos), referindo-se ao parcelamento da terra para o estabelecimento de roças. A proibição do uso do solo em Áreas de Preservação Permanente, enfatizando a área do Morro do Lampião e das dunas, associada ao declínio da atividade agrícola, fez com que a partir da década de 1970 a vegetação nativa voltasse a se regenerar, ou na fala dos entrevistados "o mato tomasse conta de tudo" (informante 6,71 anos; informante 15, 69 anos). Porém a partir dos anos 1980 , o solo passou a possuir outro valor, no caso o valor imobiliário, transformando áreas de solo rural em solo urbano, e consequentemente a vegetação nativa perdendo espaço para construções e vias públicas.
Amora (1996) afirma que no passado era inconcebível para os nativos construir na faixa de dunas próximo à praia, por perceberem a vulnerabilidade destas áreas, pela movimentação da areia, pela constante ação eólica, e por serem o principal local de drenagem das águas superficiais.

Além dos impactos sobre o ambiente natural, a urbanização também afetou o modo de vida da comunidade tradicional. Através das entrevistas foi possível elencar pontos positivos e negativos da transformação rural-urbano para a comunidade tradicional. Uma característica marcante dos diálogos dos informantes sobre a vida no passado rural foi a ênfase nas dificuldades sofridas pela falta de infra-estrutura. A ausência de transporte público, a falta de energia elétrica, a parca variabilidade de alimentos, a ausência de escola básica e posto de saúde foram citados como exemplos de tais dificuldades. A urbanização surge então como alternativa de melhoria na vida da população nativa, porém traz junto de si conflitos como a falta de segurança e a apropriação da paisagem com a construção de edifícios a beira mar. $\mathrm{Na}$ relação com o ambiente, muitas são as queixas relacionadas à falta de espaço para os quintais resultantes do parcelamento da terra, e a obstrução de antigos caminhos em meio à vegetação de restinga, nos quais faziam coleta de plantas para utilização, seja para alimento, remédio, ou outras categorias de uso.

\section{Pessoas e plantas na restinga do Campeche}

Considerando os dados das entrevistas e das turnês guiadas, foi obtido um total de 669 citações. Para análise dos dados foram consideradas apenas espécies comumente encontradas na restinga, incluindo nativas, ruderais e exóticas com distribuição espontânea, resultando em 87 espécies pertencentes a 47 famílias botânicas (Tab. 1). As famílias mais representativas foram Asteraceae, com nove espécies e Myrtaceae, com oito espécies, seguidas por Fabaceae, com cinco espécies e Bromeliaceae, com quatro espécies.

Melo et al. (2008) investigaram o conhecimento sobre espécies de restinga na comunidade do Pântano do Sul (Florianópolis, $\mathrm{SC}$ ), e obtiveram através de turnês guiadas com cinco informantes um total de 46 espécies distribuídas em 31 famílias botânicas, sendo as mais representativas Myrtaceae e Asteraceae, com seis espécies cada. Em um estudo etnobotânico comparativo sobre espécies de restinga em quatro comunidades da Ilha do Cardoso (SP) e na comunidade de Naufragados, em Florianópolis (SC), com um total de 63 informantes, Miranda \& Hanazaki (2008) obtiveram um total de 201 espécies pertencentes a 76 famílias botânicas, sendo as mais representativas Myrtaceae (25 espécies), Asteraceae (18 espécies), Poaceae (17 espécies), Lamiaceae (12 espécies) e Euphorbiaceae (10 espécies). Cabe ressaltar que neste estudo foram consideradas comunidades geograficamente distintas, e que portanto possuem uma variação florística maior quando comparado a estudos em uma única localidade, além de terem sido consideradas nas análises também espécies exóticas cultivadas. Fonseca-Kruel \& 
Tabela 1. Espécies citadas por 15 informantes do Distrito do Campeche (Florianópolis, SC). Al=alimentar; Com=combustível (lenha); Cons=construção; Ec=ecológico; $\mathrm{Fo}=$ forrageira; $\mathrm{Ma}=$ manufatura; $\mathrm{Me}=$ medicinal; $\mathrm{Or}=$ ornamental; $\mathrm{Ou}=$ outros; $\mathrm{SU}=$ sem uso. Época de uso: Passado $(\mathrm{P})$, Atual $(\mathrm{A})$ - não se aplica às categorias Ec e SU.

\begin{tabular}{|c|c|c|c|c|}
\hline Família & Espécie & Nome popular & Categoria de uso & Época de uso \\
\hline Agavaceae & Furcraea foetida (L.) Haw. & Piteira & $\mathrm{Ec}, \mathrm{Or}, \mathrm{Ma}, \mathrm{Ou}$ & $\mathrm{P}$ \\
\hline \multirow[t]{2}{*}{ Amaranthaceae } & Alternanthera brasiliana (L.) Kuntze & Penicilina & $\mathrm{Me}$ & $\mathrm{P}, \mathrm{A}$ \\
\hline & Chenopodium retusum (Moq.) Moq & Santa-Maria & $\mathrm{Me}$ & $\mathrm{P}, \mathrm{A}$ \\
\hline \multirow[t]{2}{*}{ Anacardiaceae } & Lithrea brasiliensis Marchand & Aroeira-brava, aroeira-má, aroeira-preta & SU, Ec, Com & $\mathrm{P}$ \\
\hline & Schinus terebinthifolius Raddi & $\begin{array}{l}\text { Aroeira-mansa, aroeira-boa, aroeira- } \\
\text { vermelha, aroeira }\end{array}$ & $\begin{array}{l}\text { Ma, Ec, Com, } \\
\text { Cons }\end{array}$ & $\mathrm{P}, \mathrm{A}$ \\
\hline Araliaceae & Hydrocotyle bonariensis Lam & Corcel & Ec & \\
\hline Apocynaceae & Tabernaemontana catharinensis A. DC & Quebra-dente & Ec, Me, Com, Or & $\mathrm{P}, \mathrm{A}$ \\
\hline Aquifoliaceae & Ilex dumosa Reissek & Cauna & Com & $\mathrm{P}$ \\
\hline Araceae & Philodendron $s p$ & Imbé & $\mathrm{Ma}$ & $\mathrm{P}$ \\
\hline \multirow[t]{3}{*}{ Arecaceae } & Bactris setosa Mart. & Tucum & $\mathrm{Al}, \mathrm{Ma}$ & $\mathrm{P}$ \\
\hline & Butia capitata (Mart.) Becc. & Butiá & $\mathrm{Al}, \mathrm{Ma}$ & $\mathrm{P}, \mathrm{A}$ \\
\hline & Syagrus romanzoffiana (Cham.) Glassman & Coqueiro & $\mathrm{Al}$ & $\mathrm{P}$ \\
\hline \multirow[t]{9}{*}{ Asteraceae } & Achyrocline satureioides (Lam.) DC. & Marcela & $\mathrm{Ma}, \mathrm{Me}, \mathrm{Ou}, \mathrm{Ec}$ & $\mathrm{P}, \mathrm{A}$ \\
\hline & Baccharis dracunculifolia DC. & Vassoura, vassourinha, vassoura-miúda & $\mathrm{Ma}$ & $\mathrm{P}$ \\
\hline & Baccharis trimera (Less.) DC. & Carqueja, vassoura-carqueja & $\mathrm{Me}$ & $\mathrm{P}, \mathrm{A}$ \\
\hline & Bidens pilosa $\mathrm{L}$. & Picão preto & $\mathrm{Me}$ & $\mathrm{P}, \mathrm{A}$ \\
\hline & Eupatorium casarettoi (B.L. Rob.) Steyerm. & $\begin{array}{l}\text { Vassoura-de-bicho, vassoura-carqueja, } \\
\text { vassoura-branca }\end{array}$ & $\mathrm{Ma}, \mathrm{Com}, \mathrm{Ec}, \mathrm{SU}$ & $\mathrm{P}$ \\
\hline & Eupatorium inulifolium Kunth & Erva-de-bicho, cambará & $\mathrm{Me}$ & $\mathrm{P}, \mathrm{A}$ \\
\hline & Mikania sp. & Guaco & $\mathrm{Me}$ & $\mathrm{P}, \mathrm{A}$ \\
\hline & Vernonia scorpioides (Lam.) Pers. & Mata-pasto & SU & \\
\hline & Wedelia trilobata (L.) Hitchc. & Arnica & $\mathrm{Me}$ & $\mathrm{P}, \mathrm{A}$ \\
\hline \multirow[t]{2}{*}{ Bignoniaceae } & Pyrostegia venusta (Ker Gawl.) Miers & Cipó-de-São-João & Ec, Ma, Cons & $\mathrm{P}$ \\
\hline & Tabebuia pulcherrima Sandwith & Aipê, aipé, aipê amarelo & Ma, Cons, Me & $\mathrm{P}$ \\
\hline \multirow[t]{2}{*}{ Boraginaceace } & Cordia monosperma (Jacq.) Roem. \& Schult. & $\begin{array}{l}\text { Caramona-de-gato, caramona-mansa, } \\
\text { caramona-miudinha }\end{array}$ & $\mathrm{Al}$ & $\mathrm{P}$ \\
\hline & Cordia verbenacea DC. & Caramona & $\mathrm{Al}, \mathrm{Me}$ & $\mathrm{P}, \mathrm{A}$ \\
\hline Brassicaceae & Coronopus didymus (L.) Sm. & Mastrunço & $\mathrm{Me}, \mathrm{Al}$ & $\mathrm{P}, \mathrm{A}$ \\
\hline \multirow[t]{4}{*}{ Bromeliaceae } & Aechmea lindenii E. Morr ex C. Koch & Gravatá, bromélia-de-bibitu & $\mathrm{Ec}, \mathrm{SU}$ & \\
\hline & Aechmea nudicaulis (L.) Griseb. & $\begin{array}{l}\text { Gravatá, bromélia-de-bibitu, bromélia- } \\
\text { chupechupe, bibitu }\end{array}$ & $\mathrm{Ec}, \mathrm{Al}, \mathrm{Ou}$ & P, A \\
\hline & Dyckia encholirioides (Gaudich.) Mez & Gravatá & SU & \\
\hline & Vriesiea friburgensis $\mathrm{Mez}$ & Gravatá-mole, gravatá-do-escombro & SU & \\
\hline Cactaceae & Opuntia arechavaletai Speg. & Marumbeva, arumbeva, caruá & $\mathrm{Ma}, \mathrm{SU}$ & $\mathrm{P}$ \\
\hline Calyceraceae & Acicarpha spathulata R. Br. & Roseta, roseta-das-dunas, roseta-gigante & Ec & \\
\hline Cannabaceae & Trema micrantha (L.) Blume & Grandiuva & Fo & $\mathrm{P}$ \\
\hline Celastraceae & Maytenus muelleri Schwacke & Espinheira-santa & $\mathrm{Me}$ & P, A \\
\hline Clusiaceae & Clusia criuva Cambess. & Mangue-do-morro, mangue & Com & $\mathrm{P}$ \\
\hline Commelinaceae & Commelina sp. & Mata-pasto & SU & \\
\hline Convolvulaceae & Ipomoea pes-caprae (L.) R. Br. & Cipó-da-praia, batateira-da-praia & $\mathrm{Ec}, \mathrm{Or}, \mathrm{Ou}$ & $\mathrm{P}$ \\
\hline Cucurbitaceae & Momordica charantia $\mathrm{L}$. & "Melão" & $\mathrm{Al}$ & $\mathrm{P}$ \\
\hline \multirow[t]{2}{*}{ Сyperaceae } & Androtrichum trigynum (Spreng.) H. Pfeiff. & Junco & Ec, Ma, Cons & $\mathrm{P}$ \\
\hline & Eleocharis sp. & Junco & Ma, Fo & $\mathrm{P}$ \\
\hline Dryopteridaceae & Rumohra adiantiformis (G. Fost.) Ching & Samambaia & Or & $\mathrm{P}, \mathrm{A}$ \\
\hline Ericaceae & Gaylussacia brasiliensis (Spreng.) Meisn. & Camarinha & $\mathrm{Al}$ & $\mathrm{P}, \mathrm{A}$ \\
\hline \multirow[t]{2}{*}{ Erythroxylaceae } & Erythroxylum amplifolium Baill. & Cambuim & Com & $\mathrm{P}$ \\
\hline & Erythroxylum argentinum O. E. Schulz & Pimentinha & Com, Cons, Ec & $\mathrm{P}$ \\
\hline Fabaceae Faboideae & Cajanus cajan (L.) Huth & Feijão-andum & $\mathrm{Al}, \mathrm{Me}$ & $\mathrm{P}, \mathrm{A}$ \\
\hline
\end{tabular}


Tabela 1. Continuação

\begin{tabular}{|c|c|c|c|c|}
\hline Família & Espécie & Nome popular & Categoria de uso & Época de uso \\
\hline & Desmodium incanum DC. & Pega-pega, Carrapicho & SU & \\
\hline & Indigofera $S P$ & Erva-de-tinta & $\mathrm{Ma}, \mathrm{Al}$ & $\mathrm{P}$ \\
\hline & Stylosanthes viscosa (L.) Sw. & Mela-mela & SU & \\
\hline \multirow[t]{2}{*}{$\begin{array}{l}\text { Fabaceae } \\
\text { Mimosoideae }\end{array}$} & Inga sp. & Ingá, angá & $\mathrm{Al}$ & $\mathrm{P}, \mathrm{A}$ \\
\hline & Mimosa bimucronata (DC.) Kuntze & Unha-de-gato, espinheiro & $\mathrm{Me}, \mathrm{Com}$ & $\mathrm{P}, \mathrm{A}$ \\
\hline Lamiaceae & Vitex megapotamica (Spreng.) Moldenke & Baga-de-cachorro, marmeleiro & $\mathrm{Ec}, \mathrm{Com}, \mathrm{Ou}$ & $\mathrm{P}$ \\
\hline Lauraceae & Ocotea pulchella (Nees) Mez & Canelinha, canela & Ec, Com, Cons & $\mathrm{P}$ \\
\hline \multirow[t]{4}{*}{ Malvaceae } & Malva parviflora $\mathrm{L}$. & Malva-de-dente, malva-da-praia, malva & $\mathrm{Me}$ & $\mathrm{P}, \mathrm{A}$ \\
\hline & Sida carpinifolia L. f. & Barreleira ou gaxumba & Fo, $\mathrm{Me}$ & $\mathrm{P}, \mathrm{A}$ \\
\hline & Sida rhombifloia $L$. & Varreleira & Fo, Ec & $\mathrm{P}, \mathrm{A}$ \\
\hline & Triumfetta sp. & Carrapicho & SU & \\
\hline Melastomataceae & Tibouchina urvilleana (DC.) Cogn. & $\begin{array}{l}\text { Erva-de-trovoada, flor-roxa, flor-de- } \\
\text { vento-sul }\end{array}$ & SU & \\
\hline \multirow[t]{3}{*}{ Myrsinaceae } & Myrsine coriaceae (Sw.) R. Br. ex Roem. \& Schult. & Capiroroca-branca & Ec, Ma, Cons, Com & $\mathrm{P}$ \\
\hline & Myrsine parvifolia A. DC. & Capororoquinha, capororoca-miúda & $\mathrm{Ec}, \mathrm{Ma}$, Cons, Com & $\mathrm{P}$ \\
\hline & Myrsine sp. & Capiroroca & Ec, Ma, Cons, Com & $\mathrm{P}$ \\
\hline \multirow[t]{8}{*}{ Myrtaceae } & Campomanesia littoralis D. Legrand & Gabiroba, guabiroba, gavirova, guavirova & $\mathrm{Me}, \mathrm{Al}, \mathrm{Com}, \mathrm{Ec}$ & $\mathrm{P}, \mathrm{A}$ \\
\hline & Eugenia catharinae O. Berg & Parpanguela & $\mathrm{Ec}, \mathrm{Ma}$ & $\mathrm{P}$ \\
\hline & Eugenia tomentosa Aubl. & Cabeluda & $\mathrm{Al}$ & $\mathrm{P}$ \\
\hline & Eugenia umbelliflora O. Berg & Baguaçu, Biguaçu & $\mathrm{Al}, \mathrm{Me}$ & $\mathrm{P}, \mathrm{A}$ \\
\hline & Eugenia uniflora $\mathrm{L}$. & Pitanga & $\mathrm{Al}, \mathrm{Me}, \mathrm{Com}$ & $\mathrm{P}, \mathrm{A}$ \\
\hline & Myrcia sp. & Cambuim & Com & $\mathrm{P}$ \\
\hline & Psidium cattleianum Sabine & Araçá & $\mathrm{Al}, \mathrm{Me}, \mathrm{Com}$ & $\mathrm{P}, \mathrm{A}$ \\
\hline & Psidium guajava $\mathrm{L}$. & Goiaba & $\mathrm{Al}, \mathrm{Me}, \mathrm{Com}$ & $\mathrm{P}, \mathrm{A}$ \\
\hline Nyctaginaceae & Guapira opposita (Vell.) Reitz & Maria-mole & Fo & $\mathrm{P}$ \\
\hline Orchidaceae & Epidendrum fulgens Brongn. & $\begin{array}{l}\text { Parasita, flor-parasita, orquídea, } \\
\text { parasita-do-escombro }\end{array}$ & Ec, Or & $\mathrm{P}, \mathrm{A}$ \\
\hline Passifloraceae & Passiflora edulis Sims & $\begin{array}{l}\text { Maracujá-roxo, maracujá-de-escombro, } \\
\text { maracujá-miudo, maracujá-doce }\end{array}$ & $\mathrm{Al}, \mathrm{Me}, \mathrm{Ec}$ & $\mathrm{P}, \mathrm{A}$ \\
\hline Phyllantaceae & Phyllantus sp. & Quebra-pedra & $\mathrm{Me}$ & $\mathrm{P}, \mathrm{A}$ \\
\hline Plantaginaceae & Plantago sp. & Lingua-de-vaca & $\mathrm{Me}$ & $\mathrm{P}, \mathrm{A}$ \\
\hline Polygalaceae & Polygala cyparissias A. St.-Hil.\& Moq. & $\begin{array}{l}\text { Vick-vaporub, perfume-de-iodex, } \\
\text { cânfora }\end{array}$ & SU, Me & $\mathrm{P}, \mathrm{A}$ \\
\hline Polypodiaceae & Polypodium lepidopteris (Langsd. \& Fisch.) Kunze & Samambaia, samambaia-fina & SU, Or & $\mathrm{P}, \mathrm{A}$ \\
\hline Rubiaceae & $\begin{array}{l}\text { Diodia radula (Willd. ex Roem. \& Schult.) Cham. \& } \\
\text { Schltdl. }\end{array}$ & Erva-de-lagarto & Fo, Me, SU & $\mathrm{P}, \mathrm{A}$ \\
\hline Santalaceae & Phoradendron sp. & Erva-de-passarinho & SU & \\
\hline \multirow[t]{3}{*}{ Sapindaceae } & Cupania vernalis Cambess & Combatá & Com, Cons, Ou & $\mathrm{P}$ \\
\hline & Dodonaea viscosa Jacq. & Vassoura, vassoura-vermelha & $\begin{array}{l}\mathrm{Ec}, \mathrm{Com}, \\
\mathrm{Ma}, \mathrm{Ou}\end{array}$ & $\mathrm{P}$ \\
\hline & Matayba guianensis Aubl. & Cumbatá & Com, Ma & $\mathrm{P}$ \\
\hline Smilacaceae & Smilax campestris Griseb. & $\begin{array}{l}\text { Erva-de-tostão, tripa-de-galinha, erva- } \\
\text { de-dinheiro }\end{array}$ & $\mathrm{Me}, \mathrm{Ou}$ & $\mathrm{P}$ \\
\hline \multirow[t]{3}{*}{ Solanaceae } & Solanum capsicoides All. & Tomate-de-cavalo & SU & \\
\hline & Solanum paniculatum $\mathrm{L}$. & Jurumbeva & $\mathrm{Me}$ & $\mathrm{P}, \mathrm{A}$ \\
\hline & Solanum pseudoquina A. St.-Hil. & Canema & Com & $\mathrm{P}$ \\
\hline Typhaceae & Typhasp. & Taboa & $\mathrm{Ma}$ & $\mathrm{P}$ \\
\hline \multirow[t]{2}{*}{ Verbenaceae } & Lantana camara L. & Mau-me-quer, bem-me-quer, lantana & $\mathrm{Ou}$ & $\mathrm{P}$ \\
\hline & Stachytarpheta cayennensis (Rich.) Vahl. & Gervão, gervão-preto & $\mathrm{Me}, \mathrm{Fo}, \mathrm{Ec}$ & $\mathrm{P}, \mathrm{A}$ \\
\hline
\end{tabular}


Peixoto (2004), em pesquisa realizada com pescadores em Arraial do Cabo (RJ), também focada no ambiente de restinga, obtiveram através de 15 informantes um total de 68 espécies, distribuídas em 42 famílias botânicas e novamente a mais representativa foi Myrtaceae (9 espécies), seguida por Asteraceae e Cactaceae (4 espécies cada). Observa-se a partir dos dados das pesquisas citadas que as famílias Myrtaceae e Asteraceae configuram-se como importantes fontes de recursos no ambiente de restinga, tendência já observada por Miranda \& Hanazaki (2008).

Neste estudo, além das espécies nativas, considerando como tais espécies com dispersão natural em áreas de restinga do sul do Brasil, foram incluídas nas análises espécies exóticas que possuem distribuição espontânea na área de restinga, como por exemplo, a goiabeira (Psidium guajava), espécie muito comum na região, nativa do território brasileiro porém introduzida na região sul. Foram consideradas ainda espécies de distribuição espontânea na restinga cuja origem é duvidosa, como Furcraea foetida, Lantana camara e Dodonaea viscosa.

As espécies citadas que não foram consideradas nas análises por não terem distribuição espontânea em áreas de restinga foram espécies cultivadas como, por exemplo, espécies do gênero Citrus e temperos como Mentha e Ocimum, ou espécies típicas de outros sistemas, como Rhizophora mangle e Schizolobium parahyba.

A citação de espécies cultivadas na região reflete as diferenças entre o conceito de "espécies nativas" entendido pelos informantes e o conceito científico. Para a população local espécies nativas do Campeche são aquelas usualmente encontradas na região, uma vez que os informantes ao nascerem já tiveram contato com tais plantas; entende-se que as mesmas são tão nativas quanto eles próprios.

A curva de rarefação para citações das espécies nas entrevistas (Fig. 1) aponta uma tendência para a estabilidade, e o cálculo do índice de Chao resultou em $85,88 \%$ do total esperado $\left(_{\text {sobs }}=88,{ }_{\text {Sest }}=102,7\right)$, o que significa que através das 15 entrevistas foi levantado mais que $80 \%$ do total de plantas de restinga conhecidas.

A partir dos resultados das entrevistas, os usos dados para as plantas foram agrupados nas seguintes categorias: alimentícia, combustível, construção, ecológico, forrageiro, manufatura, medicinal, ornamental, outros (ex: plantas para barreira, mistura utilizada para lavar roupas, uso místico, lúdico) e sem utilização. A categoria medicinal foi a que obteve mais citações, seguida por ecológico, combustível, manufatura e alimentícia (Fig. 2).

$\mathrm{Na}$ categoria alimentícia, o principal uso relatado foi para alimentos ocasionais, ou seja, aqueles que complementam a alimentação, mas não representam as principais fontes energéticas na dieta da população. Quatro informantes, na faixa etária 69 a 85 anos, enfatizaram a utilização na infância dos frutos de Gaylussacia brasiliensis, Psidium cattleianum, Campomanesia littoralis e Cordia verbenacea no retorno da escola, antes do almoço, quando voltavam para casa pelas

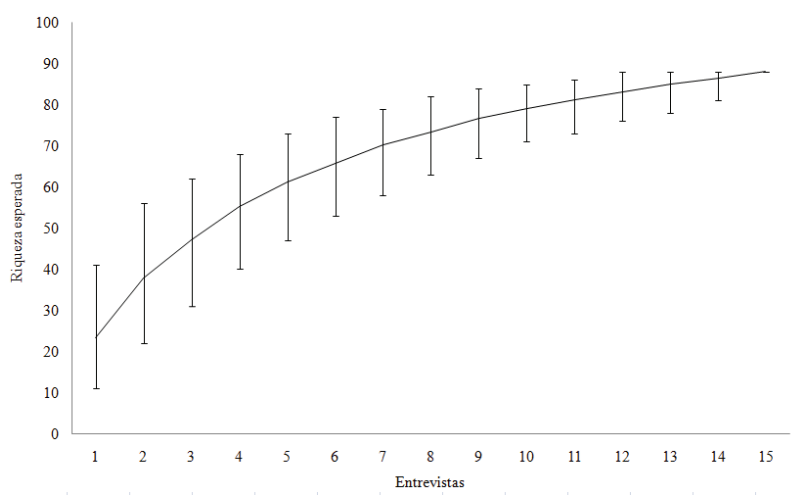

Figura 1. Curva de rarefação para plantas de restinga conhecidas por 15 entrevistados nativos do Distrito do Campeche (Florianópolis, SC).

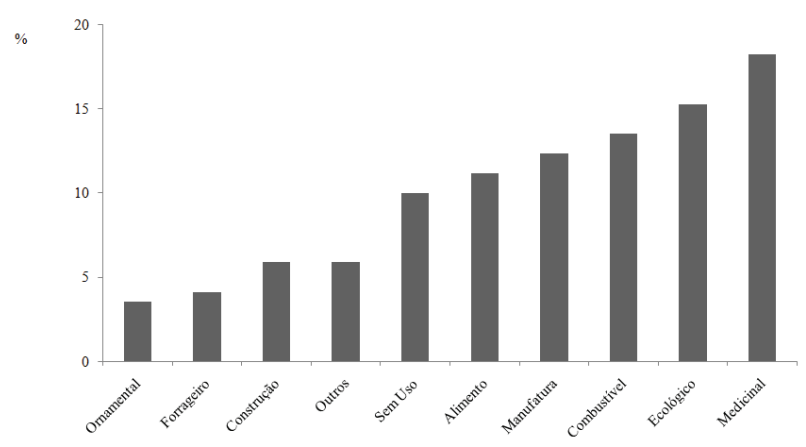

Figura 2. Porcentagem relativa de espécies por categoria de uso obtidas através de 15 entrevistas com moradores tradicionais do Campeche (Florianópolis, SC).

trilhas que cortavam a restinga. É interessante notar que ao serem questionados sobre o uso atual destas espécies os informantes afirmam que quando encontram tais plantas com frutos ainda os comem, porém ressaltam a dificuldade de encontrá-los. Analisando a região nota-se que tais espécies podem ser encontradas frequentemente nos fragmentos de restinga próximos à praia, porém não estão mais disponíveis nos caminhos utilizados pela população em geral.

$\mathrm{Na}$ categoria combustível a principal forma de utilização foi como lenha para abastecer o fogão. Dos 15 informantes, 12 ainda possuem o fogão a lenha e cinco deles fazem uso frequente do mesmo. Apesar de terem citado algumas espécies como preferidas para a lenha, dois informantes (68 e71 anos) afirmaram que toda madeira seca potencialmente vira lenha. Quando questionados sobre o uso atual, todos que ainda utilizam afirmaram que da restinga usam apenas gravetos, ou restos de podas de quintais e terrenos, uma vez que a coleta está proibida, e que as madeiras maiores são compradas.

Foram consideradas na categoria ecológico as espécies apontadas pelos informantes como possuidoras de importância para outras espécies ou para o ecossistema em geral; as principais citações foram quanto à importância para a fixação das dunas e alimento para os animais, principalmente aves. Como fixadoras de dunas foram citadas variadas espécies, e tais citações ocorreram principalmente durante 
as turnês guiadas, quando as plantas eram observadas nas dunas. Como importantes fontes de alimentos para as aves, as espécies mais citadas foram Schinus terebinthifolius e Erythroxylum argentinum.

A utilização na categoria manufatura englobou o uso de espécies como matéria prima para a fabricação de objetos (cestas, artigos de pesca, utilitários como esteiras, vassouras e travesseiros), como as usadas para a fabricação de vassouras, geralmente conhecidas pelo mesmo nome ou variações, como vassourinha, vassoura branca, vassoura miúda, vassoura carqueja, vassourão, vassoura vermelha (Tab. 1). Tais denominações para os tipos de vassouras frequentemente foram variáveis entre os informantes, apesar de haver algum consenso sobre algumas espécies, como a vassoura de bicho (Eupatorium casarettoi), chamada por este nome por apresentar associação com larvas de lepidópteros, como pôde ser registrado em uma das turnês guiadas. Outros tipos de uso como manufatura foram relatados para a construção de artefatos de pesca, como as fibras de F. foetida, utilizadas no passado para confecção de redes, ou a casca de $S$. terebinthifolius para tingimento de redes.

A utlização de plantas como forrageiras foi relatada principalmente para alimentação de gado bovino, destacando-se o uso de Guapira opposita, que segundo dois informantes (42 e 77 anos) e 13 (77 anos) seria uma das preferidas dos animais.

Para construção foram citadas espécies utilizadas tanto na base das edificações, como Cupania vernalis e espécies do gênero Myrsine, como as utilizadas para forrar, com função de telhado, como Androtrichum trigynum. Tal uso já não tem mais continuidade, uma vez que atualmente se utiliza apenas materiais comprados para a construção de edificações.

Como ornamental, a principal espécie citada foi $R u$ mohra adiantiformis, utilizada para confecção de arranjos. Outros trabalhos atestam a importância desta espécie em outras regiões, onde a coleta é mais expressiva do que a observada no local (Souza et al. 2006). Outras espécies citadas como ornamentais, Epidendrum fulgens e Ipomoea pes-caprae, chamam a atenção por suas flores coloridas e vistosas e são preservadas nos terrenos ou coletadas e replantadas nos quintais.

A categoria de uso com maior número de citações foi a medicinal. Nesta é possível notar uma mistura entre conhecimentos de moradores mais antigos e novos conhecimentos obtidos através de diversos meios, seja na interação com novos moradores, na literatura sobre plantas medicinais ou na mídia. Um exemplo de conhecimento incorporado é a utilização das folhas de C. verbenacea como anti-inflamatório, enquanto os antigos utilizavam apenas seus frutos para alimentação. Usos pela população antiga foram citados para as Myrtaceae P. cattleianum, $P$. guajava e Eugenia uniflora, sendo suas folhas utilizadas para curar problemas intestinais, como citado por Melo et al. (2008) em outra comunidade de pescadores da Ilha de Santa Catarina.
O uso de plantas medicinais persiste na comunidade paralelamente ao acesso a medicamentos industrializados, porém percebe-se que há certa insegurança em relação à eficácia dos mesmos quando não são receitados por profissionais da saúde. Aqui é importante ressaltar que há dois postos de saúde e uma policlínica na região, e que um dos postos de saúde tem trabalhado com a inserção das plantas medicinais, tendo inclusive um pequeno horto de plantas medicinais onde auxiliam os pacientes na identificação das plantas.

Ainda em relação às plantas medicinais, uma confusão em relação à identificação foi notada durante a pesquisa, quando uma informante (75 anos) durante a turnê-guiada indicou E. casarettoi vassoura carqueja, e informou que havia visto em um livro que era uma planta medicinal, provavelmente aqui confundindo com Baccharis trimera. Este fato indica uma demanda por conhecimentos mais aprofundados em relação à identificação de plantas medicinais, de forma a evitar usos errôneos.

Espécies citadas e sem utilização demonstram que há uma interação com as plantas presentes no ambiente independentemente de seu caráter utilitário. Tais plantas são reconhecidas, nomeadas, mas não possuem qualquer utilidade. Seu conhecimento pode ser explicado por algumas características que chama a atenção da população, como as flores vistosas de Tibouchina urvilleana, ou os espinhos de Triumfetta sp., ou a característica de parasitar outras plantas de Phoradendron sp.

\section{Usos no passado e no presente}

Quanto à frequência de uso no passado e no presente, as respostas dos entrevistados foram classificadas nas seguintes categorias: "raramente", "esporadicamente", "frequentemente", "quando necessário" e "quando frutifica", sendo essas duas últimas relativas às plantas medicinais e alimentíciaes, respectivamente. Para comparação da frequência de uso foram utilizadas apenas as categorias "raramente", "esporadicamente" e "frequentemente", além das respostas que indicavam uma frequência nula de uso. $\mathrm{O}$ teste chi-quadrado para independência resultou em diferença significativa na distribuição de frequências relacionadas ao uso no passado e no presente $\left(\mathrm{X}^{2}=124,628, p\right.$ $<0,0001)$. A ausência de uso de certas plantas no presente é bem maior do que no passado, assim como o uso frequente de algumas plantas era bem maior no passado do que no presente (Fig. 3), o que demonstra que havia no passado uso mais acentuado das plantas citadas nas entrevistas.

Ao justificar a ausência ou diminuição no uso de certas plantas frequentemente usadas no passado, os entrevistados citaram como principais razões a substituição por produtos encontrados no mercado, a proibição da exploração de produtos obtidos em áreas de preservação e a ausência das plantas onde antes eram encontradas.

As plantas utilizadas frequentemente no passado, cujo uso permanece frequente no presente foram as medicinais 


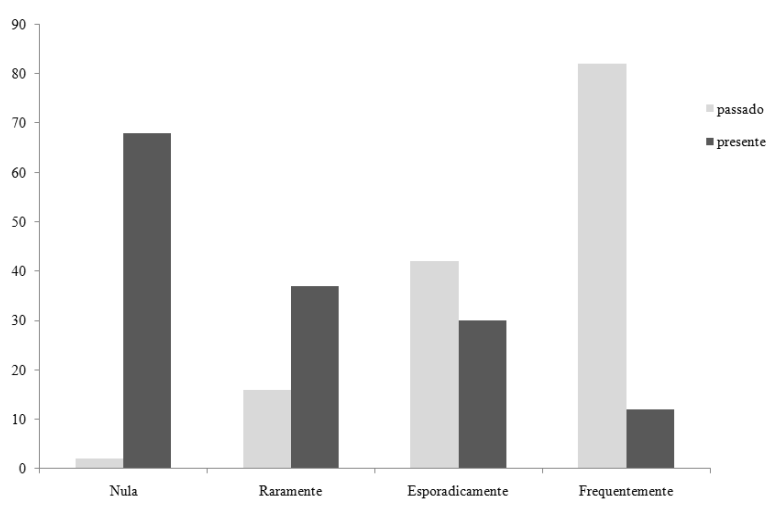

Figura 3. Frequência de citações de uso de plantas de restinga no passado e no presente por 15 informantes nativos do Distrito do Campeche (Florianópolis, SC).

Achyrocline satureoides, Coronopus didymus e Eupatorium inulifolium, as alimentíciaes P. guajava e E. uniflora, D. viscosa e E. argentinum utilizadas como lenha, R. adiantiformis utilizada como enfeite e Bacharis dracunculifolia ainda utilizada por uma informante que mantém o antigo hábito de confeccionar vassouras. Por outro lado Cajanus cajan, utilizada como medicinal e Pouteria campechiana, utilizada como alimento, eram desconhecidas no passado pelos informantes que as citaram.

A ausência de uso de plantas frequentemente utilizadas no passado pode levar a perda do conhecimento destas plantas nas gerações futuras, enquanto novos conhecimentos podem ser incorporados na comunidade. Porém, para que haja conhecimento etnobotânico sobre plantas de restinga é necessário que existam áreas onde a restinga permaneça conservada na região.

\section{Conclusões}

O conhecimento etnobotânico dos moradores tradicionais do Distrito do Campeche remonta aos tempos antigos, quando a região se caracterizava como área rural. Algumas formas de utilização das espécies citadas caíram em desuso, seja pela proibição da exploração de espécies pela legislação ambiental, seja pela troca por produtos encontrados com maior facilidade no mercado. Entretanto percebe-se que o conhecimento etnobotânico está presente e que em algumas categorias de utilização continua em desenvolvimento, como no caso das plantas medicinais. Apesar disso, são marcantes as mudanças na frequência de uso das plantas e a redução na dependência pelos recursos vegetais da restinga.

A memória da utilização de plantas no passado, junto com a aquisição de novos conhecimentos, demonstra a inserção dos conhecimentos etnobotânicos como parte da dinâmica cultural de uma sociedade em transformação. Novos hábitos, crenças e valores típicos da vida urbana vão se inserindo, mas não necessariamente extinguem a realidade anterior, vivida pelos moradores nativos da região e ainda viva em suas memórias. Além do valor do conhecimento em si, a valorização do mesmo auxilia na valorização da cultura local. Ao falar sobre as plantas utilizadas no passado os informantes ativam a memória e reconstituem a história da comunidade, localizando-se neste universo de transformações.

A presença de áreas de restinga permeando a malha urbana propicia o contato com as plantas, proporcionando um espaço onde o conhecimento etnobotânico pode continuar existindo e sendo elaborado dentro da nova configuração da comunidade urbana atual. Ao registrar o conhecimento etnobotânico de comunidades em transformação, a pesquisa científica contribui para evitar que tais conhecimentos sejam perdidos, somando esforços na valorização da cultura local associada à relação das pessoas com o ambiente de restinga.

\section{Agradecimentos}

À Coordenadoria de Aperfeiçoamento de Pessoal de Nível Superior pela concessão de bolsa através do Programa REUNI para a primeira autora; ao Conselho Nacional de Desenvolvimento Científico e Tecnológico pela bolsa de produtividade concedida à segunda autora; à equipe do Laboratório de Ecologia Humana e Etnobotânica da Universidade federal de Santa Catarina pelo auxílio na coleta de dados; ao professor Daniel Falkenberg pelo auxílio na identificação das plantas; à Viviane Stern Fonseca-Kruel, Ariane Luna Peixoto, Tânia Tarabini Castellani e Nivaldo Peroni pelos comentários e sugestões; aos moradores do Distrito do Campeche que gentilmente aceitaram participar da pesquisa e dedicaram parte do seu tempo para fornecer os dados que possibilitaram a elaboração da mesma.

\section{Referências}

Albuquerque, U.P. 2005. Introdução à etnobotânica. 2 ed.. Rio de. Janeiro, Editora Interciência.

Albuquerque, U.P.; Lucena, R.F.P. \& Neto, E.M.F.L. 2008. Seleção e escolha dos participantes da pesquisa. Pp.21-40. In: Albuquerque, U.P.; Lucena, R.F.P. \& Cunha, L.V.F.C. (Orgs.). Métodos e técnicas na pesquisa etnobotânica. 2 ed. Recife, NUPPEA.

Alcorn, J. 1995. The scope and aims of ethnobotany in a developing world. Pp. 23-39. In: Schultes, R.E. \& von Reis, S. (Eds.). Ethnobotany: evolution of a discipline. Portland, Discorides Press.

Alexiades, M.N. 1996. Collecting ethnobotanical data: An introduction to basic concepts and techniques. Pp. 54-93. In: Alexiades, M.N. (Ed.) Selected guidelines for ethnobotanical research: a field manual. Nova York, New York Botanical Garden.

Amora, A.M.G.A. 1996. O lugar do público no Campeche. Dissertação (Mestrado em Geografia) - Florianópolis, Universidade Federal de Santa Catarina.

Barbosa, T.C. 2007. Material de referência 01: Ecologia e Recursos Naturais na Planície do Campeche. Pp. 99-114. In: Tirelli, J.; Burgos, R. \& Barbosa, T.C. (Orgs.). O Campo de Peixes e os Senhores do Asfalto: memória das lutas do Campeche. Florianópolis, Cidade Futura.

Campanário, P. 2007. Florianópolis: dinâmica demográfica e projeção da população por sexo, grupos etários, distritos e bairros (1950-2050). Florianópolis, Instituto de Planejamento Urbano de Florianópolis. 
Chao, A. 1984. Non-parametric estimation of the number of classes in a population. Scandinavian Journal of Statistics 11: 210-217.

Diegues, A.C. 2004. A mudança como modelo cultural: o caso da cultura caiçara e a urbanização. Pp. 21-48. In: Diegues, A.C. (Org.). Enciclopédia caiçara: o olhar do pesquisador. Vol. 1. São Paulo, Editora Hucitec.

Diegues, A.C. \& Arruda, R.S.V. 2001. Saberes tradicionais e biodiversidade no Brasil. Brasília, Ministério do Meio Ambiente.

Falkenberg, D.B. 1999. Aspectos da flora e da vegetação secundária da restinga de Santa Catarina, Sul do Brasil. Insula 28: 1-30.

Fonseca-Kruel, V.S. \& Peixoto, A.L. 2004. Etnobotânica na reserva extrativista marinha de Arraial do Cabo, RJ, Brasil. Acta Botanica Brasilica 18(1): 77-190.

Gotelli, N.J. \& Entsminger, G.L. 2001. EcoSim: Null models software for ecology. Version 7.0. Acquired Intelligence Inc. \& Kesey-Bear.

Hanazaki, N. 2004. Etnobotânica. Pp. 37-57 In: Begossi, A. (Ed). Ecologia Humana de Pescadores da Mata Atlântica e da Amazônia. São Paulo, FAPESP/HUCITEC.

IPUF, 2009. Localização do Distrito do Campeche. Disponível em: http://www.planodiretorfloripa.sc.gov.br/arquivos_pdf/campeche. pdf (Acesso em 10/08/2008).

Melo, S.; Lacerda, V.D. \& Hanazaki, N. 2008. Espécies de restinga conhecidas pela comunidade do Pântano do sul, Florianópolis, Santa Catarina, Brasil. Rodriguésia 59(4): 799-812.

Miranda, T.M. \& Hanazaki, N. 2008. Conhecimento e uso de recursos vegetais de restinga por comunidades das ilhas do Cardoso (SP) e de Santa Catarina (SC). Acta Botanica Brasilica 22(1): 203-215.

MMA/SBF. 2002. Avaliação e identificação de áreas e ações prioritárias para a conservação, utilização sustentável e repartição dos benefícios da biodiversidade nos biomas brasileiros. Brasília, MMA/SBF.

Neves, P.C. da F. 2003. Do valor espaço ao valor no espaço no distrito do Campeche (Florianópolis - SC): Loteamento Novo Campeche e Loteamento Areias do Campeche. Dissertação (Mestrado em Geografia). Florianópolis, Universidade Federal de Santa Catarina.

Peroni, N.; Araujo, H.F.P. \& Hanazaki, N. 2008. Métodos ecológicos na investigação etnobotânica e etnobiológica: o uso de medidas de diversidade e estimadores de riqueza. Pp.199-225. In: Albuquerque, U.P.; Lucena, R.P. \& Cunha, L.V.F.C (Orgs.) Métodos e técnicas na pesquisa etnobotânica. 2 ed. Recife, NUPPEA.

Santos, A.J. 2003. Estimativas de riqueza de espécies. Pp. 19-42 In Cullen Jr, L.; Rudran, R. \& Valladares-Pádua, C. Métodos de estudo em biologia da conservação e manejo da vida silvestre. Curitiba, Editora da UFPR.

Souza, V.C. \& Lorenzi, H. Botânica Sistemática: Guia ilustrado para identificação das famílias de Angiospermas da flora brasileira, baseado em APG II. Nova Odessa, SP: Instituto Plantarum, 2005.

Souza, G.C.; Kubo, R.; Guimarães, L. \& Elisabetsky, E. 2006. An ethnobiological assessment of Rumohra adiantiformis (samambaia-preta) extractivism in Southern Brazil. Biodiversity and Conservation 15 2737-2746

Strohaecker, T.M. 2008. Dinâmica populacional. Pp. 59-73. In: Macrodiagnóstico da Zona Costeira e Marinha do Brasil. Brasília, IBAMA/MMA.

Tongco, M.D.C. 2007. Purposive sampling as a tool for informant selection. In: Ethnobotany Research \& Applications 5: 147-158. 